\title{
ESCREVIVÊNCIAS TRANS* COMO POTÊNCIA
}

\author{
Alfrancio Ferreira Dias (UFS)** \\ http://orcid.org/0000-0002-5562-0085
}

\section{RESUMO}

Neste texto, discuto uma analítica de gênero a partir do movimento de escrevivências ${ }^{1}$ trans* ${ }^{*}$. Na primeira parte deste trabalho, discuto como a escrita trans* é potencializadora do autoconhecimento trans*, legitimando, assim, novas formas de produzir conhecimento sobre tais sujeitos a partir deles mesmos, estimulando-me a descrevê-las em vez de teorizar sobre suas vidas. Na segunda parte, discuto o surgimento de uma pedagogia trans* que desenvolve o ensino, ampliando a representatividade desse conhecimento, a partir de uma abordagem pedagógica pautada nos princípios de ensinar como trans* (autorrevelação feminista que fortalece/amplia espaços de compartilhamentos das experiências trans*), ensinar sobre trans* (dar visibilidade ao universo trans* no ensino) e ensinar com epistemologias trans* (afirmar que o ensino trans*, além de ser incorporado em práticas outras de produção do conhecimento, é, em si mesmo, epistemológico, ou seja, produtor de conhecimento).

Palavras-chave: Escrevivências trans*. Epistemologias trans*. Pedagogia trans*.

\section{ABSTRACT \\ TRANS* 'ESCREVIVÊNCIAS' AS POWER}

In this text, I discuss a gender analysis stemmed from the movement of trans* Escrevivências. ${ }^{2}$ In the first part of this work, I discuss how trans* writing is a boost for trans* self-knowledge, thus legitimizing new ways of producing knowledge about such subjects from themselves, stimulating me to describe them instead of theorizing about their lives. In the second part, I discuss the emergence of a trans* pedagogy that develops teaching, broadening the representativeness of this knowledge, based on a pedagogical approach based on the principles of teaching as trans* (feminist self-revelation that strengthens/ widens spaces of trans* experiments), teaching about trans* (providing exposure to the trans* universe in teaching), and teaching with trans* epistemologies (to say that trans* teaching is not only embedded in other practices of knowledge

\footnotetext{
** Doutor em Sociologia pela Universidade Federal de Sergipe (UFS). Professor do Departamento de Educação e do Programa de Pós-graduação em educação da Universidade Federal de Sergipe (UFS). E-mail: diasalfrancio@gmail.com.

1 Neologismo aplicado às palavras em português "escrever" (escrever) e "experiência" (experiência pessoal adquirida durante a vida), implicando escrever de acordo com a vida pessoal, ou seja, da perspectiva social, racial e de gênero.

2 Neologism coined from the Portuguese words "escrever" (to write) and "vivência" (personal experience acquired during one's life), implying to write according to one's personal life, that is, from one's social, racial and gender perspective.
} 
production, it is, epistemological, itself, that is to say, producer of knowledge).

Keywords: Trans* escrevivências. Trans* epistemologies. Trans* pedagogy.

\section{RESUMEN \\ ESCREVIVÊNCIAS TRANS* COMO POTENCIA}

En este texto, discuto una analítica de género a partir del movimiento de las escrevivências trans*. ${ }^{3}$ En la primera parte de este trabajo, discuto cómo la escritura trans* es potencializadora del autoconocimiento trans, legitimando así nuevas formas de producir conocimiento sobre tales sujetos a partir de ellos mismos, estimulándome a describirlas en vez de teorizar sobre sus vidas. En la segunda parte, discuto el surgimiento de una pedagogía trans* que desarrolla la enseñanza, ampliando la representatividad de ese conocimiento, a partir de un enfoque pedagógico pautado en los principios de enseñar como trans* (auto-revelación feminista que fortalece / amplía espacios de compartimentos de las experiencias trans*), enseñar sobre trans* (dar visibilidad al universo trans* en la enseñanza) y enseñar con epistemologías trans* (afirmar que la enseñanza trans* además de ser incorporado en prácticas otras de producción del conocimiento, es, en sí mismo, epistemológico, o sea, productor de conocimiento).

Palabras Clave: Escrevivências trans*. Epistemologías trans*. Pedagogía trans*.

\section{Introdução}

Continuaremos resistindo.

Somos resilientes.

Nossos corpos rasgarão essa sociedade como navalhas, derrubando seus padrões opressores e assassinos. Direito, visibilidade e respeito a todes os corpos transvestigêneros.

Não recuaremos.

E sim, avançaremos e venceremos por nós, porque esta também será a salvação dessa sociedade pautada no machismo assassino da cisheteronorma.

Por mim.

Por nós e por todes.

(SIQUEIRA, 2017, p. 170). ${ }^{4}$

0 poema escolhido como epígrafe deste artigo, de autoria da ativista trans* Indianara Siqueira (2017), fecha o livro Nós, Trans: escre-

3 El neologismo utilizado para partir las palabras portuguesas "escrever" (escribir) y "vivência" (experiencia personal adquirida durante la vida), implicando escribir de acuerdo con su vida personal, es decir, desde su perspectiva social, racial y de género.

4 Apesar de reconhecer a natureza literária de alguns dos textos que aqui exploro, destaco que meu interesse está centrado no potencial que eles têm de produzir reflexões sobre as trajetórias existenciais de pessoas trans* e suas vivências. vivências de resistências, organizado pelo Grupo Transcritas Coletivas e publicado pela editora Litera Trans. Destaco a obra para informar a todxs de sua importância e de como ela me ajudou a entender mais sobre as vivências e experiências trans* a partir das próprias pessoas trans*. Sua leitura é indispensável nos dias hoje. Ao concluir a leitura emocionado, percebi como tais vidas importam menos e como o olhar cisgênero produz um cotidiano sofrível para elas e para outros sujeitos desviantes, assim como eu.

É um exercício diário resistir a esse olhar onipresente, pois a cisheteronorma, além de produzir marcas no meu corpo ao longo da vida, tenciona e (re)produz uma escrita acadêmica elitista, classista, racista e generificada. Por exemplo, foi-me dito numa seleção de ingresso de doutoramento que estudos de gênero, ou melhor, pesquisar sobre gênero era, necessariamente, um objeto da sociologia, e não educacional. Isso me fez lembrar de como 
a escrita acadêmica, às vezes, é produtora de assimetrias em termos de marcadores sociais da diferença. A recusa na avaliação do meu projeto estava, justamente, ligada ao fato de que ele tematizava questões de gênero e como existe uma marcação de campos disciplinares (o que é um objeto de pesquisa de educação, ou não, por exemplo) e a exclusão de objetos que tematizam gênero num campo disciplinar. Essa é uma forma de estabelecer fronteiras rígidas, primeiro, do que conta como ciência, e depois, de quais sujeitos e objetos são válidos de serem visibilizados em termos de pesquisa. Como bicha afrontosa que sou, tratei de enfrentar um docente da pós-graduação acerca do que ele havia aprendido sobre gênero em sua trajetória formativa ou que espaços de diálogo a partir de "objetos dissidentes" havia naquele programa de pós-graduação. Fiquei sem resposta e ainda fui reprovado na seleção. Claro que isso não me desanimou e tentei aprovação em outro programa, no qual consegui, e onde, ao concluir meu doutorado, disse para mim mesmo: agora vou ler por mim mesmo e pesquisar o que me dá tesão. E, já como professor universitário, me encontrei com as leituras pós-estruturalistas sobre corpos, gêneros e sexualidades, especialmente sobre os estudos queer e trans*.

Já informo que, como me disse um grande amigo e intelectual gay feminista, certo dia, numa conversa maravilhosa entre bichas: "eu não sou obrigado a nada". Assim, isso serve para destacar a rebeldia de minha escrita, bem como para dizer que não conseguirei traduzir, esclarecer ou explicar todos os termos, palavras e/ou conceitos que surgirão ao longo do texto. Calma! Tenho um objetivo com isso: provocar nas pessoas a curiosidade, o exercício da pesquisa, a necessidade de saber mais por conta própria. Então, corre para tirar possíveis dúvidas, por você mesmx.

Apesar da insubordinação de minha escrita, esclareço que as trans* identidades são cada vez mais comumente descritas usando a palavra trans juntamente com um asterisco curinga, que é indicativo das muitas identi- dades possíveis que podem estar associadas à palavra trans (RYAN, 2014), abrindo para a transgeneridade uma maior gama de significações (CATALANO, 2017; PORTER; DEAN, 2015; TOMPKINS, 2014).É um movimento político de escrita ao qual aderi em 2017. A ideia aqui é desaquendar o universo trans* nas produções acadêmicas, retirando-o de frases explicativas sobre trans* identidades dentro do texto ou, pior ainda, em notas de rodapé que apenas fornecem possibilidades restritas de definições. Certamente, não existe um consenso sobre um melhor e um verdadeiro termo que represente o universo de possibilidades sexo-genéricas que aqui discutimos, contudo, espero que seu uso não implique, necessariamente, na ideia de uma possível "conformidade de identidade e experiência que pode levar a uma excessiva simplificação e potencial quantificação e humanização de vidas trans*” (CATALANO, 2017, p. 235). Ao contrário, estou, com essa opção, denunciando como a linguagem é acionada para diminuir o potencial das trans* identidades no conteúdo escrito, distraindo seu principal foco que é ampliar as preocupações práticas que afetam a vida dessas pessoas (SPADE, 2011). E isso, por si só, é violento.

Contudo, gostaria de retomar a escolha pelo termo "escrevivências trans*" com a qual intitulo esse texto. Foi a professora Jaqueline Gomes de Jesus quem, influenciada pelos escritos da escritora negra Conceição Evaristo, nos introduziu a importância da escrita de sobrevivência para pensar as vivências de diversas pessoas trans*. Escrevivências trans*, como descrito por Jaqueline, e pelxs demais autorxs da obra e outras tantas pessoas que escrevem sobre narrativas, correspondem a reflexões e histórias de vidas trans* que não só se constroem em resistência aos discursos cisgenêros, heteronormativos e racializados, mas evocam transformações políticas.

Nas palavras de Maria Léo Araruna, que apresenta o livro Nós, trans, "temos pressa e o ímpeto de romper com as concepções feitas sobre nós a partir de um olhar cisgênero que 
coloniza nossas subjetividades" (ARARUNA, 2017a, p. 9). 0 que Maria Léo Araruna propõe, assim como toda a obra, é "silenciar a voz da cisgeneridade que é teimosa em explicar quem nós somos. E temos como objetivo fazer parte de uma trajetória que visa a autonomia dos corpos e a libertação do nosso imaginário sobre nós mesmas/os" (ARARUNA, 2017a, p. 9). Como a escrita trans* é potente e significativa. As leituras nessa seara me ensinam que o conhecimento trans* é aquele produzido por elxs mesmxs. Estou aprendendo a descrevê-lo a partir do exercício da desaprendizagem, da desaprendizagem de um modo de produzir conhecimento calcado na cisnormatividade. Decerto, esse conhecimento é decolonial, ${ }^{5}$ uma vez que propõe novas leituras as quais podem ajudar na obtenção de uma orientação não mais cisgênera e que nos exige pensar sobre as apostas de trans* visibilidade para além da academia (GREEN, 2017).

Entretanto, o que discuto nesse texto? Uma epistemologia trans* a partir desse movimento de escrevivências. Estou interessado em refletir que epistemologias estão sendo produzidas a partir das vivências e saberes trans*. E, por fim, reflito como essa epistemologia trans* potencializa noções expansivas de gênero e novas práticas pedagógicas a partir do ensino com trans*, sobre trans* e conhecimento trans*.

\section{Por uma epistemologia trans*}

Sejamos simplesmente gente em Trans.mutação Gente fora das medidas, dos processos, dos sistemas Gente fora-de-si, fora-do-mundo, fora-da-lei

Gente posta pra fora, no meio da festa, porque estava com o peito de fora,

Com ideias de fora, com o coração e a alma à mostra.

5 Tomo aqui decolonialidade como um "fenômeno histórico muito mais complexo que se estende até nosso presente, e que se refere a um padrão de poder que opera através da naturalização de hierarquias territoriais, raciais, culturais e epistêmicas que possibilitam a re-produção de relações de dominação; este padrão de poder não só garante a exploração pelo capital de alguns seres humanos por outros em escala mundial, como também a subalternização e obliteração dos conhecimentos, experiências e formas de vida daquelas pessoas que são assim dominadas e exploradas" (RESTREPO; ROJAS, 2010, p. 15).
Gente fora-de-órbita, cansada de levar foras disso tudo que aí está

Gente que transgride, que transpõe, que ultrapassa todos os limites para combater um mundo injusto, careta, cansado e cansativo. Um mundo que mais já deu o que tinha que dar, mas continua aí, firme feito rocha, insistindo em marcar sua presença machista-racista-patriarcal, cisheteronormativa, escrotamente eficiente.

Mundo de binarismos bestas e de crenças idiotas em códigos de condutas completamente vencidos, que as pessoas são doutrinadas a seguir cegamente, acriticamente, do útero ao pó da terra.

Gente que se recusa a ser uma peça fixa no jogo viciado de xadrez da sociedade, onde apenas reis, rainhas e bispos podem se mover à vontade.

Por existências transgressoras... que nos permitam transcender as possibilidades e simplesmente Ser: pluri... multi... inter... trans diverso... Viva!

Sem amarras, enquadramentos, definições, segregações, em nossas complexidades e singularidades. Não à opressão do não encaixe [...] (CARVALHAL, 2017a, p. 12-13).

Essa é uma parte do texto Transgente, de Tito Carvalhal (2017a, p. 12). Tito é um "transpirado, com 32 anos, nascido no ser-tão e radicado na babilônia soteropolitana". Conforme apresentação no livro Nós, trans (SIQUEIRA, 2017, p. 177), sua poesia se constitui no "movimento de estar sendo humano errante". Na fase de escrita do texto, se sentia uma pessoa solitária. A solidão, a depressão e o sofrimento são experiências vividas cotidianamente por muitas pessoas trans* (ARARUNA, 2017b; ARAÚJO, 2017; MORAES, 2017). Corpos em "trans.mutação", "fora das meditas, dos processos, dos sistemas". Corpos em fuga, corpos fora-de-si e fora-do-mundo, conforme expõe acima Tito Carvalhal: "Gente que transgride, que transpõe, que ultrapassa todos os limites para combater um mundo injusto, careta, cansado e cansativo" (CARVALHAL, 2017a, p. 12). Posso descrever disso que as pessoas trans* não só ultrapassam como borram as fronteiras das normas de gênero. Seus corpos, gêneros e sexualidades são dissidentes. Se comunicam, se rebelam, se reinventam, produzem histórias para serem lidas.

Segundo Pearce, Steinberg e Moon (2018), o surgimento da terminologia trans* anuncia mudança em relação a designações anterior- 
mente usadas para se referir a essas experiências. Além disso, essa proposta de nomeação se anuncia "com gênero e sexualidade representando espectros em interseção, não apenas de possibilidades, mas de experiências reais vividas" (PEARCE; STEINBERG; MOON, 2018, p. 2). Para xs autorxs, sua existência se deu a partir de uma variedade de identidades e experiências trans* que se tornaram possíveis e reconhecíveis. Não são simples histórias trans*, mais sim narrativas de "contestação e negociação sobre o significado em uma série de contextos" (PEARCE; STEINBERG; MOON, 2018, p. 2). Essas narrativas de contestação e negociação são pautas nas lutas ativistas diárias e, agora, mais fortemente, num movimento de "escrevivências de resistência", em que escritorxs trans* estão pautando uma nova dinâmica na escrita feminista e na Academia, propondo a criação de uma "Trans-língua", um conhecimento sobre elxs a partir de suas vivências e experiências (ARARUNA, 2017).

A escrita trans* passa a ser um ato político de transformação. Uma forma potente de enfrentamento da norma. Desaquendar saberes sobre gêneros e sexualidades que desestruturem e que gonguem a cisnormatididade. A norma funciona pela falha e, segundo Beatriz Bagagli (2017, p. 31), é por meio dela que vivem as pessoas trans*, pois as "relações de poder são tencionáveis". Isso porque a norma só existe e se fortifica diariamente, a partir do corpo dissidente, desviante, transviado etc. Ou seja, é na resistência que vivem as pessoas trans*, produzindo um conhecimento que transgride, tenciona e questiona a norma (BENTO, 2014, 2017). Isso se evidência nas palavras de Tito, acima referidas, ao destacar as experiências de existências transgressoras, que permitem às pessoas trans* "transcender as possibilidades e simplesmente Ser: pluri... multi... inter... trans diverso..." (CARVALHAL, 2017a, p. 12-13). Ser trans* tornou-se possível nos processos de resistir e desobedecer ao discurso cisgênero.

Aprendi com as pessoas trans* que os discursos cisgêneros impõem uma explicação ou justificativa às suas existências e vivências. Claro que essa explicação sempre se deu a partir do pensamento cisgênero, ou seja, pessoas cis refletindo e justificando a existência de pessoas não cis. E, aqui cabe retornar à tríade sexogênero-desejo como fato determinante para a (re)produção da cisheteronorma. Conforme Babagli (2017, p. 31), esse seria o problema: colocar a "cisgeneridade como escolha natural e esperada de todas as pessoas e coloca a transgeneridade como uma escolha descabida".

Sobre a ótica da cisgeneridade, a transgeneridade passa a ser uma opção desprezível e, em muitos casos, dolorosa de ser vivida. Foi a esse lugar que as pessoas trans* passaram a resistir e questionar. Nesse contexto, a escrita de resistência passou a ser um ponto de encontro comum para as pessoas tidas como estranhas, desviantes, desviadas, dissidentes. Essas escritas buscam desmistificar a opressão trans* produzida pelo conhecimento gerado nas instituições acadêmicas para desconstruir a "noção de que as vidas e experiências trans* são abjetas, anormais, ininteligíveis e impossíveis" (NICOLAZZO, 2017a, p. 1).

0 primeiro passo para essa mudança de perspectiva foi despatologizar as identidades trans*, a partir da desconstrução dos limites de gênero relacional de dois (masculino/feminino) e sua abertura para uma pluralidade de vivências de gênero. Conforme Pearce, Steinberg e Moon (2018), esse movimento se deu desde a década de 1990, quando se passou a questionar o lugar desconfortável posto para as identificações trans* no entendimento cisgênero de gênero binário (ou se nasce homem ou mulher) e de sexualidade não expansiva e contínua (desejo do homem para com a mulher ou ao contrário).

Para Butler (2017), o gênero não está inscrito de forma passiva no corpo, ele é uma tecnologia social sofisticada heteronormativa que produz corpos aderentes. Normas reiteradas pelas instituições e pela linguagem operam em atos performativos de gênero que, sendo indefinidamente reiterados, interpretados, 
ganham aparência, se renovam e se consolidam no corpo. Só que no "lugar da lei da coerência heterossexual, vemos o sexo e o gênero desnaturalizados por meio de uma performance que confessa sua distinção e dramatiza o mecanismo cultural de sua unidade fabricada" (BUTLER, 2017, p. 238). Cotidianamente as pessoas trans* nos ensinam essa experiência performativa do gênero. Vejamos a poesia de Tito Carvalhal (2017b, p. 52-53), intitulada "E agora... o que te faz homem?":

0 que te faz homem agora?

Ser um escroto,

Pegador,

Machista,

Estrupador?

Homem não chora,

Não fala de amor,

Determina

O opressor

Macho que é macho põe o falo em cima da mesa

e grita

Corpo retesado

Nenhuma delicadeza

Viril

Másculo

Não aceita ser contestado

Contrariado

Afeminado

Transcendo a colonização

Macho sim

Quero ser não

Escracho

Minha masculinidade

Transviada

Se forja é nas gentilezas

Trans-vejo

Uma buceta masculina

Destruindo a normalização

Meu corpo

Pura revolução.

É evidente e sofisticada a crítica à cisheteronormatividade proposta por Tito, evidenciando como as normas de gênero são acionadas para a (re)produção de uma masculinidade hegemônica, a qual também pode tornar-se sofrível para as pessoas inteligíveis. A subjetividade do autor transcende a esse movimento colonizador das vivências de gênero e do prazer. Ele não quer ser esse homem escravo. Sua masculinidade é reinventada por meio de gentilezas, transcende o discurso biológico com sua "buceta masculina", ressignificando a norma. Um corpo discursivo, político e revolucionário.

No corpo trans* não tem o que deu certo ou errado. Apenas corpos que se desconstroem para se reconstruir. São identidades e experiências não conformes que nos ensinam novas possibilidades de compreensão mais fluidas e não-binárias de vivências dos gêneros e das sexualidades (MONRO, 2005), ou seja, refletir o gênero como "rizoma", numa "ideia de trânsito, de devir, de viagem" (OLIVEIRA, J., 2016, p. 124). Assim, a análise deveria centrar-se não em um gênero ou em outro, mais sim no trânsito, que "reflete a relação do sujeito com as normas de se tornar sujeito, mas também com a melancolia de gênero e consequente foraclusão da impossibilidade de se ser outrx" (OLIVEIRA, J., 2016, p. 125). As narrativas trans* expandem nossa ideia cisgênera conceitual de gênero. Elas nos oferecem o olhar da resistência que desafia e desestabiliza os discursos hegemônicos de gênero, ou seja, as narrativas trans* tencionam o trânsito da (re)construção das subjetividades de gênero.

A epistemologia trans* busca um autoconhecimento (a partir do qual as pessoas trans* passem a se conhecer a partir de suas próprias leituras acerca de suas trajetórias subjetivas e de gênero) para transformar as narrativas que foram escritas sobre elas por pessoas cisgêneras (ARARUNA, 2017; NICOLAZZO, 2017a; SPADE, 2011). As pessoas trans* ainda são inesperadas na universidade (JOURIAN; SIMMONS; DEVANEY, 2015), necessitando desenvolver um "profundo reservatório de literatura a partir do qual desenhar" (NICOLAZZO, 2017a, p. 3). Para Nicolazzo (2017b), a entrada de pessoas trans* na universidade está ampliando a produção do conhecimento elaborado pelas pessoas trans*, destacando a necessidade de um autoconhecimento também das pessoas trans* como estratégia de partida para ampliação de suas narrativas, escritas por 
elas mesmas. Assim, com o surgimento de uma epistemologia trans*, caberia conhecê-la e usá -la como estratégia de agenciamento coletivo.

Conhecer-se enquanto grupo e legitimar novas formas de produzir conhecimento, como, por exemplo, uma epistemologia trans* decolonial (BRAYBOY, 2005; DELGADO BERNAL, 2002; OLIVEIRA, M., 2018; PATTON, 2016). Tais ações correspondem a uma nova postura epistemológica protagonizada pelas pessoas trans*, a qual contribui para uma desaprendizagem de gênero sob a ótica cisgênera e para a produção de uma educação libertadora (NICOLAZZO, 2017a), que despatologize e descolonize os saberes e vivências trans* (VERGUEIRO, 2017).

0 que esse momento epistemológico nos permite? Ainda não sei. De certo, ele está promovendo mudança na Academia, particularmente a partir da inserção e permanência de estudantes e pesquisadorxs trans*: coletivos ativistas estão sendo criados, começando um movimento de escrita, de pesquisa, de ensino e de teorização sobre as vivências trans*. Na tentativa de responder à questão, acredito que essa é a ideia da revolução trans*: "Nós nos apoderamos daquilo que nos colocam como sendo a única mensagem possível, e nos empoderamos daquilo que a gente pode falar de nós mesmos" (JESUS, 2016, p. 222), ou seja, entender as experiências trans* em vez de teorizar sobre suas experiências vividas (CATALANO, 2017).

\section{Por uma pedagogia trans*}

Nós, pessoas trans, em geral, temos muito o que falar para as pessoas cis. Já temos toda uma oralitura - uma literatura oral - sobre nós mesmas e sobre dissidências corporais, e a linguagem escrita é mais um campo de divulgação e produção que deve ser disputado por nós. E nos últimos tempos, nós temos criado muita coisa. Eu vejo muitas/os jovens trans no meio virtual que escrevem, em redes sociais e em blogs, sobre as nossas realidades e especificidades, e isso é muito rico, é resistência! Algumas/alguns de nós têm essa escrita mais acadêmica, voltada para a pesquisa, para a investigação, e eu espero que esse número cresça. (JESUS, 2017, p. 143-144).

Ao propor uma reflexão acerca de uma pedagogia trans*, não quero e nem pretendo afirmar que as pessoas trans*, de modo geral, xs pesquisadorxs e docentes trans*, de modo mais específico, possuem um método, uma forma ou metodologias de ensinar, de pesquisar e de produzir conhecimento. Para mim, isso seria retomar a ideia do "encaixe" que tenho cotidianamente desaprendido. A proposta seria refletir sobre como fomos ensinadxs, como aprendemos, como vivenciamos a aprendizagem, ao considerarmos que conhecimento foi privilegiado, quem estava/está autorizadx a falar e, sobretudo, sobre o que se fala(va). Sem dúvida, não foi sobre o ponto de vista das pessoas não cis. Neste sentido, trazer uma passagem do pensamento de Jaqueline Gomes de Jesus (2017) para abrir essa discussão é extremamente pertinente, tendo em vista que a partir dela tenho aprendido a importância de refletirmos sobre interseccionalidade e invisibilidade trans*. Jesus (2017) propõe uma inversão reflexiva sobre o pensamento produzido a partir das pessoas cis. As pessoas trans* têm "muito o que falar para as pessoas cis", a partir de suas autonarrativas, saberes sobre "dissidências corporais" e as escrevivências trans*. Tais estratégias tornaram-se um caminho de produção, de divulgação e de disputa.

Propositalmente, pergunto a você que lê comigo esse texto: já leu um texto de uma pessoa trans*? Pesquisou o que as pessoas trans* têm a nos dizer sobre corpo, gênero, sexualidade e outros marcadores? Que autorxs você privilegia para fundamentar sua escrita e suas investigações? Você, assim como eu, provavelmente foi colonizado por um conhecimento eurocêntrico que, conforme Jesus (2016) destaca, genocidiou outros saberes, como o dos povos indígenas e dos povos africanos, por muito tempo. ${ }^{6} \mathrm{Com}$

6 Esse epistemicídio é uma forma de silenciamento e invisibilidade de pessoas dissidentes, de gênero, de raça e etnia, por exemplo, na produção do saber acadêmico. Para saber mais, ver Megg Oliveira (2017). 
Jaqueline, aprendi mais ainda a dar sentido à interseccionalidade e a avaliar como essa perspectiva me ajuda a compreender as estruturas de opressão. Essa é uma das contribuições da pedagogia trans* pensar de forma decolonial ${ }^{7}$ e interseccional. Pretendo dar algumas pistas de como ela processa a partir das descrições de pessoas trans*.

A primeira contribuição que destaco é a do processo criativo dissidente para a academia, ou seja, uma variedade de formas possíveis de falar, dizer e de se expressar cientificamente (JESUS, 2016). 0 conhecimento não necessariamente é transmitido por uma pessoa, a que o "possui" e de uma única forma. A pedagogia trans* propõe a libertação do uso de uma fonte referenciada, pois existem múltiplas fontes de conhecimento, em especial as não tradicionais. Utilizando o exemplo da construção de gênero a partir da vidência, como proposto por Jaqueline, uma pergunta interessante é enunciada: "Mas quem não enxerga como vive e pensa o gênero?" (JESUS, 2016, p. 228). Realmente, eu nunca havia sequer refletido acerca disso. Como construímos uma visualidade de gênero e como estamos presxs a um gênero "como imagem construída”. Como videntes é possível visualizar suas formas, mas quem não enxerga? Como essa construção se processa? Alguém já se perguntou sobre isso? Ou melhor, já perguntou a uma pessoa cega como ela constrói suas imagens de gênero? Ou os motivos da sua pouca participação ou ausência na Academia, nos eventos científicos (em especial, feministas e ativistas) e em outros espaços? Provavelmente, não. Assim como eu, você é privilegiadx e enxerga. Daí a importância da

7 "Tais verdades [que na retórica da colonialidade estão pautadas em binarismos hierarquizantes colonizado $\mathrm{x}$ colonizador], no sentido foucaultino do termo, forjaram o feixe de condições a partir das quais são constituídas as identidades nacionais e os sentidos disponíveis na cultura para significar as formas de vida que se realizam em seu território geográfico e discursivo. Nesse contexto de possibilidades limitadas de subjetivação, emergem também os significados sociais atribuídos aos gêneros e às sexualidades, em termos da replicação, em contornos particulares e transversais a cada nova época situada, da rígida matriz ocidental" (SILVA, 2017, p. 80). interseccionalidade, para ir além do visível, da fala, dos discursos. Ela deve se processar na prática, no dia a dia, tornar-se diferente no processo de "olhar o outro, ouvir o outro, mas também permitir que o outro também fale" (JESUS, 2016, p. 230).

O segundo aspecto que destaco é uma pedagogia como gênero. Necessariamente, nunca fixa, mas em trânsito. 0 objetivo não é conhecer ou ensinar os gêneros, mas sim engajar-se e responder a ele conforme é realizado, negociado (PLATERO; DRAGER, 2015; SEFFNER; REIDEL, 2015; WELLS, 2017). Para Kristopher Wells (2017), o gênero é um evento contínuo, que precisa ser constantemente desafiado e questionado através de seu encontro "vivido". Para ele, isso se torna em uma verdadeira experiência de aprendizado: aquela que está sempre em formação. A pedagogia trans* nos ajuda na reflexão do gênero significado como um local de aprendizagem.

0 ponto de partida para isso é questionar o que há para aprender e o que precisa ser desaprendido. Xs professorxs trans* nos convidam para o espaço pedagógico da "experiência vivida para construir nossa compreensão do gênero como um processo contínuo e interminável. É um conhecimento sempre em formação e esperando para ser (re) descoberto" (WELLS, 2017, p. 6). Ao questionar o que há ou precisa ser aprendido nesse "local de aprendizagem", estamos também questionando a estabilidade hegemônica de gênero, para transgredir de uma pedagogia da impossibilidade culturalmente enraizada para uma pedagogia potencializadora e transformadora a partir do engajamento, das negociações e das vivências.

A terceira contribuição da pedagogia trans* que pretendo discutir aqui é a do ensino trans*. Esta perspectiva é desenvolvida por Kathryn S. Jaekel e Z Nicolazzo (2017), a partir de suas experiências enquanto professorxs trans* no Programa de Ensino Superior e Assuntos Estudantis, Reino Unido (Higher Education and Student Affairs - HESA). Ambos partiam da reflexão sobre a prática, questionando o quanto 
se engajavam no "ensino trans*" como um modelo pedagógico que projetava para conceituar a pedagogia que desenvolviam. Perguntar, teorizar, pensar sobre a inserção e abordagem de gênero nos seus próprios programas era uma forma de constituir uma pedagogia e gestão de sala de aula para informar suas práticas de ensino, já reconhecendo pouca amplitude das discussões que se centrassem especificamente nas experiências professorxs e pessoas trans*.

Para Jaekel e Nicolazzo (2017), ao conceituar sobre o ensino trans*, pode-se fomentar o aumento da representatividade e do conhecimento trans*, centrado nas suas próprias experiências trans*. Isso não necessariamente significa dizer que ambos pretendem ensinar para ou sobre as pessoas que se identificam dentro do universo trans*, visto que o significado de "ensinar trans*" é superior a essa compreensão. Para eles, "ensinar trans*" é uma abordagem pedagógica que "consiste em três partes principais: ensinar como, ensinar sobre e ensinar com epistemologias trans*. Para nós, 'ensinar trans' mantém as tensões de quem somos e quem somos vistos, como operamos na academia e como nos engajar na aprendizagem" (JAEKEL; NICOLAZZO, 2017, p. 168, grifo do autor). "Ensinar trans*" passa a ser uma estratégia pedagógica de contestação, que questiona a constituição e a reprodução da cisheteronorma como a legítima e única perspectiva de gênero.

0 corpo trans* é uma política de contestação, o qual é acionado como um meio de produzir conhecimento sobre gênero e seu trânsito. Assim, "ensinar trans*" passa a ser uma prática de ensino vivida, a partir da potência da escrita, do pensar e agir das pessoas trans*. Ela consiste em pesquisar diferente, não mais sob a perspectiva cisgênera, mais sim sendo o ensino como um trabalho transdisciplinar, que junte uma maior variedade de conhecimento. Uma pedagogia própria, que se centraliza nos seus próprios corpos, vozes e experiências. Ela é influenciada, segundo Jaekel e Nicolazzo (2017), nas leituras dos estudos queer, pós-estruturalismo, pós-modernismo, feminismo, teoria da raça crítica, política trans* crítica e interseccionalidade. É uma pedagogia das margens (CONCEIÇÃO, 2017; HOOKS, 1984, 1994; SPADE, 2011) que parte de temas que por muito tempo foram negligenciados na produção do conhecimento e nas vivências acadêmicas.

Quero retornar aqui ao significado de uma abordagem pedagógica que consiste em ensinar como, sobre e com epistemologias trans*, proposto por Jaekel e Nicolazzo (2017). Observo que essa abordagem também vem sendo introduzida por outrxs pesquisadorxs, a exemplo Lucas Platero e Harsin Drager (2015), Lucas Platero e José Antonio Langarita (2016) e, no Brasil, mais fortemente por Jaqueline Gomes de Jesus (2016). Para essxs professorxs, a prática docente é uma experiência pessoal que produz rupturas a partir de suas corporalidades e de seus discursos de questionamento da cisheteronorma. 0 fruto dessas vivências trans* é a reflexão sobre outras formas de ensinar e de fazer educação.

Nessa perspectiva, "ensinar como trans*", para Jaekel e Nicolazzo (2017, p. 170), é desenvolver uma "autorrevelação feminista", constituindo uma abordagem pedagógica que personaliza o "instrutor na tentativa de diminuir a hierarquia aluno-professor, além de proporcionar a oportunidade de validar a diversidade e a diferença”. Nessa prática abrem-se espaços de compartilhamento das experiências trans* para ilustrar as complexidades de como o gênero pode ser e estar em trânsito e, principalmente, um olhar não apenas do ponto de vista cisgênero. Contudo, por que o distanciamento do olhar cisgênero? Porque é necessário romper com a cisgeneridade que não entende as complexidades do universo trans*, que estimula um conhecimento generificado no qual, quase sempre, as pessoas trans* não foram consideradas como sujeitos ou partícipes de seus processos

A materialidade do corpo trans* é uma potente ferramenta para desconstruir noções 
binárias de ensino, pois como esses corpos estão em trânsito, eles desestruturam a visualidade de gênero cisnormativa. Conforme Jaekel e Nicolazzo (2017, p. 169), como suas "transnidades" estão inscritas em seus nossos corpos, nelas os corpos "encontram presença muito corpórea em espaços de sala de aula para ser um momento importante de ruptura, em que nós podemos trabalhar as fraquezas da norma em relação ao gênero". É na fraqueza da norma que se encontra a potência de ensino como trans*, sendo imperativo desaprender o olhar cisgênero que compôs a visualidade trans*, na tentativa de ajudar "os alunos a entender melhor que gênero é mais do que uma identidade, ele medeia tudo, da experiência ao sucesso acadêmico" (JAEKEL; NICOLAZZO, 2017, p. 169). Essa compreensão de gênero como devir e como vivência é fortemente discutida por Nicolazzo (2017b) em Trans* in college: transgender student's strategies for navigating campus life and the institutional politics of inclusion, uma leitura indispensável para pensarmos acerca das pessoas trans* nas universidades.

Ensinar sobre trans*, ainda para Jaekel e Nicolazzo (2017), é potencializar e dar visibilidade ao universo trans* no ensino, dada a ausência das pessoas trans*, dos corpos trans* e do conhecimento trans* em espaços, processos e objetos formativos ligados à educação. Um exemplo interessante disso é a situação dos livros didáticos no Brasil, os quais se configuram uma das mais importantes e influenciadoras ferramentas pedagógicas da educação básica. Quando sua inserção foi possível nas salas de aula brasileiras, isso se deu a partir das ideias cisgêneras, conforme apontam os autores, sendo sua discussão muitas vezes ligadas ao: "onde as colocamos" ou "o que fazemos com essa população", desvalorizando as narrativas trans* e as silenciando, ou "empurrando as vozes trans* para a periferia" (JAEKEL; NICOLAZZO, 2017, p. 170). Especificamente, as discussões sobre a população trans* nas escolas e nas universidades no Brasil estão centradas no uso dos ba- nheiros (FARRINGTON, 2016), do nome social (CORREA, 2017; LIMA, 2013) e do alojamento estudantil (NICOLAZZO; MARINE, 2015), não oportunizando refletir sobre o processo de formação, as estratégias de acesso e permanência, bem como sobre as potencialidades das questões trans* no currículo (ANDRADE, 2012; DIAS, 2014; DIAS; CARVALHO; OLIVEIRA, J., 2016; DIAS; MENEZES, 2018; FRANCO; CICLINI, 2015; LONGARAY; RIBEIRO, 2015; SALES, 2018).

Ensinar com epistemologias trans* é afirmar que o ensino trans*, além de ser incorporado (ensino como trans*) e orientado (ensino sobre trans*), é epistemológico (JAEKEL; NICOLAZZO, 2017). Esses autores destacam que no cotidiano das práticas pedagógicas, os conhecimentos trans* podem ser disseminados e incluídos nos cursos, bem como sua inserção pode potencializar espaços através dos quais se pode se chegar ao conhecimento trans*. Assim, através do ensino trans*, "podemos chegar a novas formas de conhecimento centradas no trans*, maneiras pelas quais podemos usar para continuar o projeto de expandir noções sobre o que, como, quando e onde o gênero pode existir" (JAEKEL; NICOLAZZO, 2017, p. 171).

A quarta contribuição da pedagogia trans* que gostaria de discutir é a que está sendo desenvolvida no Brasil por várias pessoas trans*, muito fortemente ligada ao movimento de escrevivências e ativismo de resistência. Muitas delas já destaquei ao longo do texto, mas gostaria de destacar aquelas que me influenciaram a refletir sobre gênero a partir da margem. São elas: Jaqueline Gomes de Jesus, Megg Rayara, Adriana Sales e Adriana Lohanna dos Santos.

Com Jesus (2016, p. 219) aprendi a questionar a forma pela qual o conhecimento cis é produzido na academia quando discute os "processos de criação sobre perspectivas de dissidências". A partir de elementos afrocentrados e de uma linguagem diferente, essa autora desenvolve uma crítica sofisticada à forma pela qual o conhecimento é produzido na univer- 
sidade. Como mulher negra trans* e filha de santo, ela utiliza a perspectiva da interseccionalidade para refletir acerca da potencialidade do ato de ouvir a outra pessoa e que todxs que compõem esse lugar possam fazer parte desse processo de fala e de escuta. Para Jaqueline Jesus (2016), por muito tempo a universidade esteve distante das margens, produzindo um conhecimento sobre as margens e compondo um lugar para esse sujeito.

Essa ideia de Academia está sendo desconstruída com abordagens dissidentes, junto às quais a escrita trans* tem contribuindo amplamente. A autora propõe um processo de escrita dissidente e processada no dia a dia. Um conhecimento negro, indígena, rural, afro-religioso, de pessoas com deficiência e das ruas, que são outras fontes de conhecimento e de produção não privilegiadas. Chega de um conhecimento sobre o outro sem o outro. É preciso "olhar o outro, ouvir o outro, mas também permitir que o outro também fale" (JESUS, 2016. p. 230), potencializando as aulas e as pesquisas desenvolvidas na universidade e fora dela. Especificamente no que se refere ao ato de pesquisar, Jaqueline Jesus (2016) nos ajuda a refletir sobre a necessidade de ampliarmos a forma de vermos e fazemos pesquisa sobre pessoas trans*, não mais as vendo como objetos de pesquisa, mas como pessoas que produzem conhecimento, num ato de pesquisar "com" as pessoas trans*, visto que as pessoas trans* têm muito a nos dizer sobre as suas vivências e como as descrevemos para a Academia.

Conheci a Megg Rayara Gomes de Oliveira durante I Conferência Internacional de Estudos Queer, que aconteceu na Universidade Federal de Sergipe (UFS), em abril de 2018. Ela estava participando de uma mesa redonda sobre educação queer e trans*. Fiquei encantado com ela e com sua pesquisa de doutoramento, e o quanto ela tem trabalhado para desconstruirmos o lugar cisheterossexual na Academia. Seu objetivo foi identificar os "elementos que incidem nos processos de subjetivação das experiências negras que fogem à norma cis heterossexual" (OLIVEIRA, M., 2018, p. 161), a partir do conceito de interseccionalidade e (auto)biografias.

A pesquisa da Megg evidenciou a existência de um vocábulo pretx como "categoria de análise e não como simples adjetivo, bem como as categorias gay afeminado, viado e bicha" (OLIVEIRA, M., 2018, p. 161), debatendo-as sem fixá-las "numa oposição declarada às visões essencialistas que generalizam existências desconsiderando os múltiplos processos que as envolvem" (OLIVEIRA, M., 2018, p. 161). Assim, a pesquisa de Megg contribui para refletirmos sobre as potencialidades das crianças dissidentes no campo da educação, especialmente as vivências e experiências negras para a problematização interseccional de gênero, sexualidade e raça nas salas de aulas e nos espaços educativos.

A pesquisa de doutorado de Adriana Sales (2018) problematiza a temática das travestilidades e a escola. A tese questiona a forma como fazemos pesquisas com pessoas trans*, a partir do diálogo, que no seu caso nos ensina que as travestis - aqui inseridas no universo trans* que discuto - "disparam relações diretas com suas corporalidades, sexualidades e gêneros nômades, que rompem com as referências binárias heterossexuais e nos apresentam outras nuances de configuração nos processos de subjetivação humana" (SALES, 2018, p. 9). Para Adriana Sales (2018, p. 9), as experiências escolares travestis elaboram outros conhecimentos a partir da potência dos seus corpos e de suas vivências, apontando para um "currículo queer e nos brindam com outros modos de produção de conhecimentos (da vida) e contestação aos processos de exclusão". Um currículo como vida.

Por último, gostaria de destacar a importância dos saberes de Adriana Lohanna dos Santos. A Lohanna, como eu a chamo, é uma mulher trans* ativista e professora da educação básica, mestra em educação. Tive o privilégio de conviver com Lohanna durante seu mestrado. Foi a primeira pesquisa em nível de mestrado 
realizada por uma pessoa trans*, sobre formação de pessoas trans* no ensino superior no estado de Sergipe, Brasil, onde moramos. De fato, foi a partir de Lohanna que iniciei minha convivência com pessoas não cis, passando a me desconstruir dia após dia, pois minhas experiências de ensino e de pesquisa até aquele momento eram pautadas pela cisgeneridade, embora sempre a contestasse. Lembro-me de uma de nossas conversas quando ela refletia acerca da inviabilidade do amor trans*, sobre como as pessoas cis pensam o gênero e a sexualidade como fixos, sobre como o corpo trans* abre espaços para novas aprendizagens de gênero e, principalmente, como o gênero é negociado na escola. Dito isso, destaco a sua pesquisa desenvolvida junto ao Programa de Pós-graduação em Educação da Universidade Federal de Sergipe (UFS), a qual foi titulada por Lohanna como Formação das pessoas transexuais na Universidade Federal de Sergipe: enfrentamento e resistência das normas de gênero no espaço acadêmico (SANTOS, 2018). Seu objetivo foi "analisar o processo de formação e permanência das pessoas transexuais na Universidade Federal de Sergipe, refletindo sobre suas trajetórias de vida como estudantes universitári@s e as estratégias de enfrentamento e resistências das normas de gênero" (SANTOS, 2018, p. 9), a partir de entrevistas narrativas com sete estudantes trans*.

A pesquisa evidenciou: o reconhecimento da identidade trans* através do espaço universitário, e como são experienciadas essas vivências dentro do cotidiano acadêmico; as dificuldades do uso do banheiro na universidade; o silenciamento dentro das salas de aulas; o uso do nome social a partir de Portaria; a criação e implementação do ambulatório de atendimento a pessoas transexuais (Ambulatório Trans*), no campus de Lagarto; o surgimento de coletivos ativistas na Universidade Federal de Sergipe, contribuindo para a socialização dos saberes trans* a partir de reuniões e eventos, como a Semana da Visibilidade Trans*. A pesquisa de Lohanna Santos (2018) é importante para a universidade, pois a partir dela é possível destacar fragilidades no atendimento à população trans* e, o mais importante, elaborar políticas institucionais trans* inclusivas.

Jaqueline, Megg, Adriana e Lohanna são pesquisadoras que me influenciam a pensar o conhecimento trans* não mais a partir de pessoas cis ou do conhecimento produzido por pesquisadorxs cis, mas sim por elas mesmas, pesquisadoras trans* e protagonistas da escrita acadêmica não cis sobre pessoas não cis, ou seja, do conhecimento trans* com e a partir de pessoas trans*.

\section{Conclusão}

Este texto é um ponto de partida de minha escrita para a análise de gênero como um movimento teórico-conceitual. Com ele começo a rasgar concepções teórico-metodológicas de gênero que não mais me satisfazem, visto que elas sempre me fixavam, e os estudos e leituras queer e trans* passaram a ter uma influência no surgimento dessa minha perspectiva de escrita mais pós-identitária. Estou tentando, me familiarizando, me permitindo ir. Para onde? Não sei. Apenas estou indo e mais feliz agora. Não sei se consegui evidenciar a perspectiva queer e pós-identitária da analítica de gênero nesta escrita e, assim, peço desculpas às pessoas que concluíram sua leitura. Talvez, por ser a primeira prática nesse sentido, precise de mais axé e, claro, de muitas leituras solidárias.

Neste texto discuto uma analítica de gênero a partir do movimento de escrevivências trans*, na qual penso gênero a partir dos saberes e vivências trans*. Assim, penso que as pessoas trans* estão desenvolvendo uma epistemologia trans*, potencializada por suas existências, vivências e saberes. A escrita trans* é um potente instrumento de transformação social e de questionamento do conhecimento produzido sobre trans* por pessoas cisgêneras. A escrevivências trans* contribuem para a despatologização das identidades trans* e para a desconstrução dos limites da análise de gênero 
cisgênera para a compreensão de vivências de gêneros mais fluidas e não-binárias. Tal escrita é potencializadora do autoconhecimento trans* que legitima novas formas de produzir conhecimento sobre trans* a partir das pessoas trans* e que nos estimula a descrever o conhecimento sobre as pessoas trans* (o qual é produzido por elas mesmas), em vez de teorizar sobre suas vidas.

Um outro aspecto importante deste texto é a potência da pedagogia trans*, que está transformando os espaços educativos a partir de processos criativos dissidentes. Assim, as pessoas trans* nos ajudam a refletir a pedagogia como gênero, para que nos engajemos a respondê-lo conforme sua realização, visto que é um evento vivido de modo contínuo. A pedagogia trans* também potencializa um ensino trans* que amplia a representatividade do conhecimento trans*, a partir de uma abordagem pedagógica que consiste nos princípios de ensinar como trans* (autorrevelação feminista que potencialize espaços de compartilhamentos das experiências trans*), ensinar sobre trans* (dar visibilidade ao universo trans* no ensino) e ensinar com epistemologias trans* (é afirmar que o ensino trans*, além de ser incorporado e orientado, é epistemológico).

\section{REFERÊNCIAS}

ANDRADE, L. N. Travestis na escola: assujeitamento e resistência à ordem normativa. 2012. 300 f. Tese (Doutorado em Educação) - Universidade Federal do Ceará (UFC), Fortaleza, 2012.

ARARUNA, M. L. O que é esse livro? In: GRUPO TRANSCRITAS COLETIVAS. Nós Trans: escrivivências de resistência. Belo Horizonte: Litera Trans, 2017a. p. 9-11.

ARARUNA, M. L. Desistir de mim mesma: um diálogo entre transfobia e depressão. In: COLETIVAS, G. T. Nós Trans: escrivivências de resistência. Belo Horizonte: Litera Trans, 2017b. p. 26-29.

ARAÚJO, L. K. Processo de expulsão. In: GRUPO TRANSCRITAS COLETIVAS. Nós Trans: escrivivências de resistência. Belo Horizonte: Litera Trans, 2017. p. 54-54.
BAGAGLI, B. P. Orientação sexual na identidade de gênero a partir da crítica da heterossexualidade e cisgeneridade como normas. Letras Escreve, v. 7, n. 1, p. 137-164, 2017.

BENTO, B. A reinvenção do corpo: sexualidade e gênero na experiência transexual. Natal: EDUFRN, 2014.

BENTO, B. Transviad@s: gênero, sexualidades e direitos humanos. Salvador: EDUFBA, 2017.

BRAYBOY, B. M. J. Toward a tribal critical race theory in education. The Urban Review, n. 37, p. 425-446, 2005. Disponível em: https://www.researchgate.net/ publication/225812554_Toward_a_Tribal_Critical_ Race_Theory_in_Education. Acesso em: 20 jun. 2019.

BUTLER, J. P. Problemas de gênero: feminismo e subversão da identidade. Rio de Janeiro: Civilização Brasileira, 2017.

CARVALHAL, T. Transgente. In: GRUPO TRANSCRITAS COLETIVAS. Nós Trans: escrivivências de resistência. Belo Horizonte: Litera Trans, 2017a. p. 12-13.

CARVALHAL, T. E agora... o que te faz homem? In: GRUPO TRANSCRITAS COLETIVAS. Nós Trans: escrivivências de resistência. Belo Horizonte: Litera Trans, 2017b. p. 52-53.

CATALANO, C. J. Resisting coherence: trans men's experiences and the use of grounded theory methods. International Journal of Qualitative Studies in Education, v. 30, n. 3, p. 234-244, 2017. Disponível em: https://www.tandfonline.com/doi/abs/10. 1080/09518398.2016.1254301? journalCode=tq se20. Acesso em: 20 jun. 2019.

CONCEIÇÃO, N. Interseccicionalidade e psicologia feminista. Salvador: Devires, 2017.

CORREA, M. A. Subjetividades em trânsito: nome social, travestilidades e transexualidades em duas universidades públicas do sul do Brasil. 2017.379 f. Tese (Doutorado Interdisciplinar em Ciências Humanas) - Programa de Pós-Graduação Interdisciplinar em Ciências Humanas da Universidade Federal de Santa Catarina (UFSC), Florianópolis, 2017.

DELGADO BERNAL, D. Critical race theory, Latino critical theory, and critical raced-gendered epistemologies: recognizing students of color as holders and creators of knowledge. Qualitative Inquiry, n. 8, p. 105-126, 2002. Disponível em: https://journals. 
sagepub.com/doi/10.1177/107780040200800107. Acesso em: 20 jun. 2019.

DIAS, A. F. Como as escolas educam corpos nas práticas pedagógicas? Revista Tempos e Espaços em Educação, v. 7, n. 12, p.15-28, 2014. Disponível em: https://doi.org/10.20952/revtee.v0i0.2958. Acesso em: 17 abr. 2020.

DIAS, A. F.; CARVALHO, M. E. P.; OLIVEIRA, D. A. Notas sobre o processo de inclusão/ exclusão de uma professora transexual. Revista da FAEEBA - Educação e Contemporaneidade, v. 25, n. 45, p. 145158, 2016. Disponível em: https://www.revistas. uneb.br/index.php/faeeba/article/view/2291. Acesso em: 20 jun. 2019.

DIAS, A. F.; MENEZES, C. A. A. Que inovação pedagógica a pedagogia queer propõe ao currículo escolar? Revista Tempos e Espaços em Educação, São Cristóvão, SE, v. 10, n. 23, p. 37-48, 2017. Disponível em: https://seer.ufs.br/index.php/revtee/article/ view/7443. Acesso em: 03 jan. 2020.

FARRINGTON, D. Nearly a dozen states sue U.S. government over transgender policies. NPR, 25 maio 2016. Disponível em: http://www.npr.org/sections/ thetwo-way/2016/05/25/479484932/11-statessue-u-s-governmentover-transgender-policies. Acesso em: 09 jan. 2019.

FRANCO, N.; CICLINI, G. A. Professoras trans brasileiras em seu processo de escolarização. Estudos Feministas, Florianópolis, v. 23, n. 2, p. 325-346, maio/ago. 2015. Disponível em: https://www.scielo.br/scielo. php?pid=S0104-026X2015000200325\&script=sci abstract\&tlng=pt. Acesso em: 20 jun. 2019.

GREEN, K. M. Trans* movement/trans* moment: an afterword. International Journal of Qualitative Studies in Education, n. 30, p. 320-321, 2017. Disponível em: https://www.tandfonline.com/doi/ abs/10.1080/09518398.2016.1274064?journalCo de=tqse20. Acesso em: 20 jun. 2019.

HOOKS, B. Feminist theory: from margin to center. Boston, MA: South End Press, 1984.

HOOKS, B. Teaching to transgress: education as the practice of freedom. New York: Routledge, 1994.

JAEKEL, K. S.; NICOLAZZO, Z. Teaching trans*: strategies and tensions of teaching gender in student affairs preparation programs. Journal for the Study of Postsecondary and Tertiary Education, n. 2, p. 165-179, 2017. Disponível em: http://www. jspte.org/Volume2/JSPTEv2p165-179Jaekel3688. pdf. Acesso em: 20 jun. 2019.
JESUS, J. G. de. As guerras de pensamento não ocorrerão nas universidades. In: COLLING, L. Dissidências sexuais e de gênero. Salvador: EDUFBA, 2016. p. 217-232.

JESUS, J. G. de. Um pouco sobre interseccionalidade e invisibilidade trans. In: GRUPO TRANSCRITAS COLETIVAS. Nós Trans: escrivivências de resistência. Belo Horizonte: Litera Trans, 2017. p. 192-194.

JOURIAN, T. J.; SIMMONS, S. L.; DEVANEY, K. C. “We are not expected": Trans* educators (re)claiming space and voice in higher education and student affairs. TSQ: Transgender Studies Quarterly, n. 2, p. 431-446, 2015. Disponível em: https://read.dukeupress.edu/tsq/articleabstract/2/3/431/79319/We-Are-Not-ExpectedTrans-Educators-Re-Claiming. Acesso em: 20 jun. 2019.

LIMA, M. L. C. 0 uso do nome social como estratégia de inclusão escolar de transexuais e travestis. 2013. 185 f. Tese (Doutorado em Psicologia Social) - Pontifícia Universidade Católica de São Paulo (PUC/SP), São Paulo, 2013.

LONGARAY, D. A; RIBEIRO, P. R. C. Espaços educativos e produção das subjetividades gays, travestis e transexuais. Revista Brasileira de Educação, Rio de Janeiro, v. 20, n. 62, p. 723-747, jul./set. 2015. Disponível em: https://www.scielo.br/scielo. php? pid=S1413-24782015000300723\&script=sci abstract\&tlng=pt. Acesso em: 20 jun. 2019.

MONRO, S. Beyond male and female: poststructuralism and the spectrum of gender. International Journal of Transgenderism, v. 8, n 1, p. 3-22, 2005. Disponível em: https://www. tandfonline.com/doi/abs/10.1300/J485v08n01_ 02? journalCode=wijt20. Acesso em: 20 jun. 2019.

MORAES, A. Soldado. In: GRUPO TRANSCRITAS COLETIVAS. Nós Trans: escrivivências de resistência. Belo Horizonte: Litera Trans, 2017. p. 87-99.

NICOLAZZO, Z. Imagining a Trans* epistemology: what liberation thinks like in postsecondary education. Urban Education, p. 1-26, 2017a. Disponível em: https://journals.sagepub. com/doi/abs/10.1177/0042085917697203. Acesso em: 20 jun. 2019.

NICOLAZZO, Z. Trans* in college: Transgender students' strategies for navigating campus life and the institutional politics of inclusion. Sterling, VA: Stylus, 2017b.

NICOLAZZO, Z; MARINE, S. B. "It will change if people keep talking": Trans* students in college 
and university housing. Journal of College and University Housing, v. 42, n. 1, p. 160-177, 2015. Disponível em: https://eric.ed.gov/?id=EJ1093901. Acesso em: 20 jun. 2019.

OLIVEIRA, J. M. Trânsitos de gênero: leituras queer/ trans* da potência do rizoma gênero. In: COLLING, L. Dissidências sexuais e de gênero. Salvador: EDUFBA, 2016. p.109-132.

OLIVEIRA, M. R. G. 0 diabo em forma de gente: (r) existências de gays afeminados, viados e bichas pretas na educação. 2017. 190 f. Tese (Doutorado em Educação) - Universidade Federal do Paraná (UFPR), Curitiba, 2013.

OLIVEIRA, M. R. G. Trejeitos e trajetos de gayzinhos afeminados, viadinhos e bichinhas pretas na educação. Revista Periódicos, v. 1, n. 9, p. 161-191, 2018. Disponível em: https://portalseer.ufba.br/ index.php/revistaperiodicus/article/view/25762. Acesso em: 20 jun. 2019.

PATTON, L. D. Disrupting postsecondary prose: Toward a critical race theory of higher education. Urban Education, n. 51, p. 315-342, 2016. Disponível em: https://journals. sagepub.com/doi/10.1177/0042085915602542. Acesso em: 20 jun. 2019.

PEARCE, R.; STEINBERG, D. L; MOON, I. Introduction: the emergence of 'trans'. Sexualities, p. 1-10, 2018. Disponível em: https://journals.sagepub. com/doi/abs/10.1177/1363460717740261. Acesso em: 20 jun. 2019.

PLATERO, R.; DRAGER, E. H. Two trans* teachers in Madrid. Transgender Studies Quarterly, v. 2, n. 3, p. 447-463, 2015. Disponível em: https://read.dukeupress.edu/tsq/articleabstract/2/3/447/79336/Two-Trans-Teachers-inMadridInterrogating-Trans. Acesso em: 20 jun. 2019.

PLATERO, R. L.; LANGARITA, J. A. La docencia encarnada, sexuada y generizada. Dos experiencias incómodas. Pedagogia i Treball Social. Revista de Ciències Socials Aplicades, v. 5, n. 1, p. 57-78, 2016. Disponível em: https://revistes. udg.edu/pedagogia_i_treball_social/article / view/22163/25931. Acesso em: 20 jun. 2019.

PORTER, C. J.; DEAN, L. A. Making meaning: identity development of black undergraduate women. NASPA Journal About Women in Higher Education, n. 8, p. 125-139, 2015. Disponível em: https:// www.researchgate.net/publication/282999478_ Making_Meaning_Identity_Development_of_Black_ Undergraduate_Women. Acesso em: 20 jun. 2019.
RESTREPO, E.; ROJAS, A. Inflexión decolonial: fuentes, conceptos y cuestionamientos. Popayán, Colombia: Editorial Universidad del Cauca, 2010.

RYAN, $\mathrm{H}$. What does trans* mean, and where did it come from? [Web log post]. Slate. 2014. Disponível em: http://www.slate.com/blogs / outward/2014/01/10/trans_what_does_it_mean and_where_did_it_come_from.html. Acesso em: 04 out. 2018.

SALES, Adriana. Travestis brasileiras e escolas (da vida): cartografias do movimento social organizado aos gêneros nômades. 310 f. Tese (Doutorado em Psicologia) - Programa de Pósgraduação em Psicologia da Universidade Estadual Paulista (UNESP), Assis, SP, 2018.

SANTOS, A. L. Formação das pessoas transexuais na Universidade Federal de Sergipe: enfrentamento e resistência das normas de gênero no espaço acadêmico. 2018. 90 f. Dissertação (Mestrado em Educação) - Universidade Federal de Sergipe (UFS), São Cristóvão, SE, 2018.

SEFFNER, F.; REIDEL, M. Transvestite and transsexual teachers: the "high heels pedagogy". Creative Education, n. 6, p. 2372-2383, 2015. Disponível em: https://www.scirp.org/journal/paperinformation. aspx? paperid=62205. Acesso em: 20 jun. de 2019.

SILVA, D. C. P. Atos de fala transfóbicos no ciberespaço: uma análise pragmática da violência linguística. 2017. Dissertação (Mestrado em Letras) - Programa de Pós-graduação em Letras, Universidade Federal de Sergipe (UFS), São Cristóvão, SE, 2017.

SIQUEIRA, I. Continuemos resistindo. In: GRUPO TRANSCRITAS COLETIVAS. Nós Trans: escrivivências de resistência. Belo Horizonte: Litera Trans, 2017. p. 173-174.

SPADE, D. Normal life: Administrative violence, critical trans politics, and the limits of the law. Brooklyn, NY: South End Press, 2011.

TOMPKINS, A. Asterisk. TSQ: Transgender Studies Quarterly, n. 1, p. 26-27, 2014. Disponível em: https://read.dukeupress.edu/tsq/ article/1/1-2/26/91872/Asterisk. Acesso em: 20 jun. 2019.

VERGUEIRO, V. Despatologizar é descolonizar. In: GRUPO TRANSCRITAS COLETIVAS. Nós Trans: escrivivências de resistência. Belo Horizonte: Litera Trans, 2017. p. 109-112.

WELLS, K. Transgender teachers: the personal, pedagogical, and political. Journal of Homosexuality, 
n. 12, p. 1-69, 2017. Disponível em: https://www.

Recebido em: 30/07/2019

tandfonline.com/doi/abs/10.1080/00918369.20

Revisado em: 30/03/2020

17.1380989. Acesso em: 20 jun. 2019.

Aprovado em: 08/04/2020

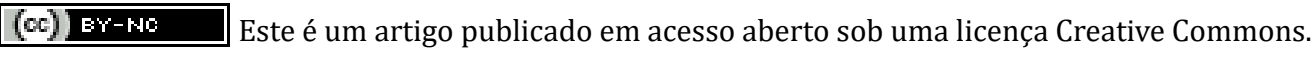

